Revista de la red interuniversitaria de estudios sobre las literaturas rioplatenses contemporáneas en Francia

6 | 2011

Juan José Saer. archivos, memoria, critica

\title{
Paisaje desde el andén
}

\section{Sergio Delgado}

\section{OpenEdition \\ Journals}

Edición electrónica

URL: http://journals.openedition.org/lirico/179

DOI: $10.4000 /$ lirico. 179

ISSN: 2262-8339

Editor

Réseau interuniversitaire d'étude des littératures contemporaines du Río de la Plata

Edición impresa

Fecha de publicación: 1 diciembre 2011

Paginación: 129-141

ISBN: 2-9525448-5-9

ISSN: 2263-2158

\section{Referencia electrónica}

Sergio Delgado, «Paisaje desde el andén », Cuadernos LIRICO [En línea], 6 | 2011, Puesto en línea el 01 julio 2012, consultado el 01 mayo 2019. URL : http://journals.openedition.org/lirico/179 ; DOI :

10.4000/lirico. 179

\section{(9) $(\mathbb{Q} \Theta \Theta$}

Cuadernos LIRICO está distribuido bajo una Licencia Creative Commons Atribución-NoComercial-

SinDerivar 4.0 Internacional. 


\title{
PAISAJE DESDE EL ANDÉN ${ }^{1}$
}

\author{
Sergio Delgado \\ Universidad de Bretagne-Sud, HCTI
}

\section{El andén, la terminal}

ara comenzar, una imagen. Pertenece a Rubén Darío, al relato
autobiográfico de su llegada en tren a Santiago de Chile, vi-
niendo desde Valparaíso, una mañana de noviembre o diciembre de 1886. Es una imagen de joven poeta, al parecer honesta, al menos por cierto efecto de transparencias, donde el autorretrato se esboza a través de la mirada del otro. En este caso la mirada desilusionada de un "político opulento" que había ido a la estación de trenes para recibir a Darío, esperando encontrar seguramente otro tipo de "poeta centroamericano", desilusión en la que el joven, por su parte, se ve reflejado:

Me envolvió en una mirada. En aquella mirada abarcaba mi pobre cuerpo de muchacho flaco, mi cabellera larga, mis ojeras, mi jacquecito de Nicaragua, unos pantaloncitos estrechos que yo creía elegantísimos, mis problemáticos zapatos, y sobre todo mi valija ${ }^{2}$.

Esa mirada ajena y distante, cuyo recuerdo ha atravesado un siglo tan arduo y tan particularmente pródigo en figuras de jóvenes poetas, con todo lo que representa, en su complejidad pero también en su torpeza, es la imagen que quisiera evocar ahora, como para comenzar a hablar del tema del viaje y la poesía. Esa mirada que se deposita sobre un joven, que no es todavía el poeta Rubén Darío - nos encontramos en la víspera, dos años antes, de la publicación de $A z u l . .-$, pero que venía

\footnotetext{
${ }^{1}$ Este trabajo retoma las notas de un dossier preparado para la revista Zama, dirigida por Noé Jitrik (Instituto de Literatura Hispanoamericana, Universidad de Buenos Aires), de próxima aparición, y el texto de una conferencia dictada en la Universidad de Paris IVSorbonne, en marzo de 2009, en el marco del seminario "Poésie et réalité" organizado por CRIMIC-PIAL.

${ }^{2}$ Rubén Darío, La vida de Rubén Dario escrita por él mismo, Caracas, Biblioteca Ayacucho, 1991, p. 34
} 
precedido, por diversas razones, más bien equívocas, por la presunción de una determinada "promesa". La llegada a Santiago, tal como la contemplamos a partir de su propia descripción, parece condensar todos estos temas. La imagen del personaje del relato autobiográfico aparece aquí reflejada, como en un espejo, sí, pero como en esos espejos de las ferias, graciosamente deformantes, que por momento agrandan y por momentos achican las figuras, en este caso la del joven poeta y de su no menos incierto destino.

Esta imagen tiene, además, la virtud de permanecer y llegar hasta nosotros gracias al recuerdo de Darío y también, lo que será el objeto de este trabajo, gracias a un poema de Juan José Saer.

Hablar de la relación entre viaje y literatura significa todo esto: hablar, por supuesto, del viaje en sí, esa experiencia única en la vida de todo individuo -escriba o no poesía a partir de ella-, donde un cuerpo es sometido al encanto y espanto, a un mismo tiempo, de la geografía y la política, pero significa también pensar esos momentos de inmovilidad, previos o posteriores a las llegadas y partidas, incuestionables aunque difíciles de percibir en el ajetreo de espacios, lenguas y mundos. Las dos cosas entonces -barcos, trenes, aviones, pero también: muelles, andenes, aeropuertos-, como motivo de algunos poemas de Juan José Saer y, por qué no, como condición de su obra, por lo menos de su poesía.

Si bien el viaje es un viejo tema poético, cuya genealogía hunde sus raíces en la poesía épica occidental, ha sido descuidado por la crítica moderna. Puede ser comprensible y si se quiere lógico, porque es un lugar común de la crítica que, en el momento de definir la especificidad de la poesía, una de sus condiciones básicas sea la ausencia de referentes. Y esto toca en especial lo autobiográfico: el viaje, el relato de un viaje, el Diario de viaje, ponen justamente en conflicto los parámetros espaciales, temporales y biográficos con los cuales estamos habituados a leer la poesía.

Esta constatación, si es acertada, resulta una curiosa verdad en el contexto de la poesía hispanoamericana, una poesía en la que, si consideramos su etapa "moderna" (o modernista), a partir de José Martí y Rubén Darío, el viaje aparece como una de las claves de su constitución. Es lo que propone Lezama Lima en La expresión americana con la figura de la "ausencia posible". Esta figura, indudablemente compleja y por supuesto que paradójica (o, para decirlo en términos de Lezama: contrapuntística), implica como condición de lo americano la ausencia 
del escritor de su territorio. Sobre todo la comprensión de que esta ausencia no es un elemento necesariamente negativo sino, por el contrario, un poder: la ausencia posible; esta figura, lejos de señalar una falta, una debilidad, un vacío, marca más bien el misterio de lo que nace a una nueva realidad e inventa su expresión.

Para Lezama, por otra parte, el prototipo de esta tradición de "ausencias" es José Martí, aquel poeta que hace posible, con su hacer y con sus versos -o con el hacer de sus versos- un nuevo espacio, a un mismo tiempo geopolítico (la independencia de Cuba) y literario (es uno de los pocos "raros" americanos del olimpo fundador modernista postulado por Rubén Darío). Dice Lezama: "José Martí representa, en una gran navidad verbal, la plenitud de la ausencia posible"3. Cuando dice esto, Lezama piensa en los poemas de Martí sobre Cuba, pero sobre todo en el Diario, la crónica de ese regreso, definitivo y fatal, a partir del desembarco en la isla, del poeta y del guerrero, a la búsqueda de la independencia de la patria. Es justamente en el Diario donde se produce esa suerte de "natividad verbal", esa "plenitud de la ausencia". Desde el Diario es posible releer toda su poesía, desde Ismaelillo hasta los Versos libres... ¿Acaso no puede pensarse toda la poesía de Martí como un diario de viaje que culmina con el retorno?

La poesía de Saer, pensada desde el tema del viaje, se inscribe en esta tradición americana.

\section{La condición del viajero}

Al hablar de viaje no me refiero aquí únicamente al tema del exilio, que en todo caso es una de sus posibilidades: un viaje responde a una gama variada de motivos, a veces evidentes pero por lo general inciertos, que la geografía y la historia terminan por revelar pero que en muy contados casos justifican. En algunas ocasiones, no pocas, el viajero se despide y regresa sin terminar de comprender lo que le ha pasado, lo que le está pasando. El viaje es antes que nada desconcierto y aprendizaje, una manera de estar en el mundo, habitándolo en el interior de sus contradicciones. En este contex to debemos recordar las palabras que Saer escribió a propósito de los Viajes de Sarmiento:

\footnotetext{
${ }^{3}$ José Lezama Lima, La expresión americana, edición de Irlemar Chiampi, México, Fondo de Cultura Económica, 1993, p. 146.
} 
Me parece adivinar aquello que, más allá del político, del ideólogo y del polemista, hace de Sarmiento un escritor: la capacidad, a pesar de la firmeza casi monomaníaca de sus ideas, de dejarse maravillar por todo lo que en la realidad diversa y adversa las contradice. De esta hospitalidad a lo antagónico nace su literatura. ${ }^{4}$

Se suele considera el concepto de "hospitalidad" en un sólo sentido, es decir el de quien recibe a un viajero o el del viajero que espera ser bien recibido, pero muy pocas veces desde la perspectiva contraria, condición básica de todo buen huésped, que implica la dificultad a asimilar al otro, o mejor dicho "lo otro", lo distinto. Lo que nos interesa ahora es estudiar, justamente, en qué medida la escritura incorpora este problema.

Si bien Saer nunca escribió, propiamente, un libro de viajes, en cierto modo gran parte de sus textos lo vislumbran. Relatos como "El viajero", por supuesto, pero también "Desde el extranjero" o "A medio borrar" (aunque éste último, más bien, como preparación de una partida), incluidos todos en La mayor (escrito los primeros años de la vida nueva de Saer en Francia), novelas como El entenado, Glosa, La pesquisa, Las nubes, La grande, o un tratado como El río sin orillas, tienen el viaje o más precisamente al viajero, como uno de sus motivos centrales. Y si bien la obra de Saer parece concentrarse en un lugar inmóvil, habría que preguntarse si esa Zona, que su narrativa explora sin cesar, no es acaso un espacio definido menos por la permanencia que por las idas $\mathrm{y}$ vueltas de sus personajes.

Algunos ensayos de Saer reflexionan sobre el tema del viaje o la condición del viajero. En especial "Entre dos aguas", escrito para un encuentro en Saint-Nazaire sobre literatura y multilingüismo y publicado en 2004 en un libro colectivo. Allí retoma ideas desarrolladas en otros trabajos, como por ejemplo "Exilio y literatura" o "Caminaba un poco encorvado" de El concepto de ficción, y datos dejados caer aquí y allá en distintos reportajes. Pero pocas veces encontramos todos estos temas dichos así y expuestos de una manera, como él mismo lo confiesa: "demasiado clara, demasiado simple". La simplicidad es en todo caso engañosa. Saer recorre todos los problemas de la adaptación a la vida y la lengua extranjeras, tocando su centro más oscuro, lo inadaptable: "en todo exilado queda siempre un residuo irreductible al cambio, un nudo

\footnotetext{
${ }^{4}$ Juan José Saer, "Sobre los Viajes", en El concepto de ficción, Buenos Aires, Ariel, 1997, p. 66 .
} 
íntimo de extrañeza y de distancia que lo obliga a menudo a traducir los datos del presente a un código que subsiste del pasado".

Ahora bien: ¿de qué manera ese "nudo íntimo de extrañeza y distancia" actúa o motiva la escritura?

\section{La nota y el movimiento}

Desde Tristes de Ovidio, esos poemas que son a un mismo tiempo relato del viaje al exilio y carta enviada desde el extranjero, esa Tomes (actual Rumania), cerca de la desembocadura del Danubio, en el límite de lo que para un ciudadano romano significaba el mundo civilizado; desde Tristes se viene escribiendo este tema. Y esos versos de Ovidio que se dicen escritos durante el viaje, para dar cuenta del dolor de los primeros tiempos del exilio, son extrañamente los cimientos de una fundación: la del poeta occidental y su relación con lo biográfico. "Todos los [versos] de este pequeño libro que acabas de leer los he compuesto durante un viaje atormentado" (Tristes, I, 11). No es improbable que esos poemas se hayan escrito, como a veces lo explicitan en un juego, en todo caso, probablemente retórico, en el barco mismo, en medio de una tormenta, durante el viaje o en el momento de llegar. La espuma del oleaje furioso golpea el rostro del poeta y llena su boca de sal... Como sea, nace aquí una tradición poética donde lo biográfico, ante la contingencia, necesita el espejo de la distancia para mostrar lo distinto, la alternativa, la brusquedad de ese particular encuentro con lo otro que es un viaje.

Es el caso, también, de "Notas en vivo (sept-oct. 1982)", una transcripción del propio Saer de una de sus libretas de viajes, que integra el Dossier preparatorio de Glosa en la edición crítica de Julio Premat ${ }^{5}$. Saer conservó esta libreta, que comenzó a escribir en 1982 y cuyas anotaciones llegan hasta octubre de 2000, y en un momento pasó a máquina sus primeras páginas, agregándole un título. Ignoramos su verdadero propósito y su explicación de incluirlo entre los materiales de preparación de Glosa es, en verdad, insuficiente ${ }^{6}$. Es cierto que existe

\footnotetext{
${ }^{5}$ Juan José Saer, El entenado y Glosa, edición dirigida por Julio Premat, Nueva Serie Colección Archivos, vol. 61, Córdoba, Universidad de Poitiers-Editorial Alción, 2010, pp. 390-401.

${ }^{6}$ Cfr. el siguiente reportaje, incluido en la edición de Archivos: Julio Premat, Diego Vecchio y GracielaVillanueva, "Entrevista a Juan José Saer del 4 de marzo de 2005", ibid., pp. 923-932.
} 
una relación entre estas notas y la escritura de la novela, pero es cierto también que estas notas pueden ser leídas en un contexto más amplio, es decir como el largo registro de la vuelta a la Argentina, luego de una ausencia de seis años, que va de marzo de 1976 hasta septiembre de 1982. El diario del regreso al país natal marca, indudablemente, la escritura de Glosa, pero también de novelas como La Pesquisa o La grande y de ensayos como El libro sin orillas.

Se trata de "notas", de una escritura fragmentaria, simple pero eficaz, tomadas al parecer "en vivo", como suele proclamarse, muchas veces de manera irresponsable, en la jerga de los noticieros de televisión, pero también como los bocetos que realiza un pintor, en plein air, o un poeta viajero como Ovidio: "las circunstancias y el lugar te darán consejo" (Tristes, I, 92). Y aquí encontramos la práctica del escritor que se ejercita, como un anatomista, un fisonomista o un paisajista, en la vista, en el tacto, en la escucha, dejándose llevar por la variedad del mundo, aunque cristalizando y congelando, como en una instantánea, lo que observa afuera, en las calles de la realidad: "Un hombre se saca los lentes y sigue caminando. Ha estado mirando en una vidriera los resultados de la lotería."

Anotaciones rápidas, pero insondables, como "Dónde empieza la lluvia”, llamados íntimos de atención sobre el lenguaje: “¿Cuál es su gracia?", que tientan el haikú o el epigrama y que al mismo tiempo confluyen hacia el relato de viaje: de un viaje de París a la Argentina en el año 1982, pero también, en otra escala, de numerosos pequeños desplazamientos: de Buenos Aires a Santa Fe, en esta ciudad a lo largo de sus calles (por San Martín, como los personajes de Glosa, hacia la plaza de mayo) o a través de su parque del Sur, pero también de Santa Fe hacia el norte, hacia Arroyo Leyes, o de Santa Fe hacia Paraná y luego de Paraná a Villa Urquiza, o finalmente desde Santa Fe hacia el Sur, hacia Rosario, pasando por Coronda...

Y también poemas breves.

Concretamente hay dos poemas en esta Libreta de viajes que luego serán incorporados a El arte de narrar, cuyo tema es el viaje. Es el caso de "En avión" y "El Graal". Hay que señalar que estos poemas no aparecen transcriptos en "Notas en vivo" (cuya fecha, repetimos es 
de 1982) y serán incorporados al final de la segunda edición de El arte de narrar (UNL, 1988), al final de la sección "Noticias secretas"7. En cambio se transcriben en "Notas en vivo", cuidadosamente, las anotaciones de las páginas anteriores y posteriores de la Libreta. Y también el poema "Cantar de amigo", inédito (aunque aparece ahora en el Dossier de la edición de Archivos).

Del estudio de las versiones de estos dos poemas en el Libreta, se pueden comprobar por lo menos tres cosas:

1. El poema "En avión" es incorporado a El arte de narrar sin modificaciones, es decir que no vuelve a ser trabajado y conserva su condición de "nota de viaje". En este caso se mantiene el mismo principio que rige la transcripción de las otras notas de la libreta y así este poema puede perfectamente incluirse, pese a su exclusión, en la categoría textual que diseña el título, es decir como "Nota en vivo". A esto contribuye además su brevedad.

2. Distinto es el caso de "El Graal", que es modificado y ampliado (se agregan nueve versos). Es decir que la libreta, además de servir de "anotador" del viaje, funciona también como Cuaderno Borrador del poema.

3. Los lugares y las fechas de los poemas, que en ambos casos se corresponden al viaje de 1982, son borrados en El arte de narrar (o en todo caso están apenas indicados en la datación del período, establecido por la sección "Noticias secretas": 1976-1982).

Muchos poemas de "Noticias secretas" hacen referencia a viajeros célebres, reales o imaginarios. Es el caso, por demás elocuente, desde su título mismo, de los poemas: "Nuevas aventuras de Robinson Crusoe" o "La historia de Cristóbal Colón"; es también el caso del poema "Islas", donde se evoca el viaje de Paul Gauguin a la Polinesia. Y también el caso de "En avión":

El viejo mar naranja que disipa

la niebla de la mañana

y las columnas de Hércules

como los dioses, hoy ausentes,

las veían.

\footnotetext{
${ }^{7}$ Es decir que no aparecen, porque no habían sido escritos todavía, en la primera edición de El arte de narrar (Caracas, Fundarte, 1977).
} 
"Las columnas de Hércules", a las que hace referencia el poema, son los peñones que marcan el estrecho de Gibraltar, que celebran al héroe griego, viajero por excelencia, y que marcaron durante mucho tiempo los límites del mundo conocido, la frontera de los navegantes del Mediterráneo. Aquí se hace alusión, indudablemente, a toda una tradición de viajeros que dejaron atrás la vieja Europa para dirigirse hacia lo desconocido. Salvo que ahora el paso de las columnas se hace "en avión". El poema habla de Hércules, de Ulises, de Colón, de Crusoe, de Gauguin, pero también del mismo Saer, si pensamos su texto en relación con el viaje de 1982 de regreso a la Argentina.

De la misma manera podemos leer el poema "El Graal", donde el viaje es evocado ahora no en clave personal, sino en función de un proyecto colectivo. Este es el poema, en la versión de la libreta:

El mar destila incertidumbre, la montaña perplejidad; y el propio cuerpo no abandona, por nada del mundo, su secreto. El viaje se volvió errabundeo, y al aura solidaria manada. En la llanura inmóvil, el cansancio nos visita: todo esto podía haber sido de este modo o de algún otro, el tiempo hubiese preferido correr para adelante o para atrás y abstenerse de salir, indiferente, la luna.

Si bien desde el título, la lectura orienta la interpretación del tema en función de la búsqueda mística del cáliz sagrado, el santo "graal", en el interior del poema este objetivo cultural y simbólico se pierde. Y se pierde doblemente, si leemos los versos con los que termina, en su reescritura: "[...] Confusos, vacilamos: / salimos a buscar no sabemos qué, / ya no nos acordamos bien cuándo".

Desde el comienzo, entonces, el objetivo sugerido por el título se borronea, porque no se encuentra lo que se busca (el "graal"), pero también porque parece estar perdiéndose el motivo del poema, confundiéndose sus referentes históricos. Es indudable que el grupo, evocado en el "nosotros", no alude a los caballeros del ciclo artúrico sino, más bien, a una generación de artistas e intelectuales argentinos que floreció en los años sesenta, a la que Saer pertenece, que vio sus sueños aniqui- 
lados por la sangrienta y triste historia de la década siguiente. En este sentido, si volvemos a leer estos versos, en la versión definitiva: "y el aura / solidaria, retirándose, / nos transformó en manada", ese "aura solidaria" hace pensar en Juan L. Ortiz, concretamente en el poema "Ah, mis amigos, habláis de rimas..."; pensar en esa "red de sangre" que "os salva del vacío"... Desde fines de los 50 cuando este poema de Ortiz se publica, desde principios de los 60 cuando es leído por un grupo de jóvenes que se reunían en Paraná o Colastiné, hasta 1978, con la muerte del poeta y las imposibilidades de la época, cuando el aura se retira... Tantas cosas han pasado. Tantas.

Estos dos poemas pueden ser considerados conjuntamente (así están dispuestos en El arte de narrar, uno detrás del otro), dado que proponen los mismos desafíos de lectura. Están emparentados también por su pertenencia a la misma Libreta de viajes. Pero tampoco hay que olvidar que una lectura estrictamente en función de esta Libreta, acentúa los aspectos autobiográficos e históricos, la relación del poema con la realidad, con lo actual.

De todos modos ambas lecturas, la que se hace desde la historia cultural (el viaje de Hércules, el viaje de los caballeros del ciclo artúrico) y la que se hace desde la historia reciente, individual o solidaria, son igualmente posibles. La oscilación, la duda, el entrar y salir de esa "frontera de la realidad" pertenece a la naturaleza misma de estos poemas.

\section{El joven y el viejo poeta}

Volvamos a la imagen del joven poeta que evocamos al comienzo. En cierto modo hay dos imágenes nítidas en la poesía de Saer: la del joven y la del viejo poeta. Inicio y fin del viaje. Dos puntas de un mismo ovillo. La primera concentra esa carga de futuro, incertidumbre, sufrimiento de quien se dispone a partir; la segunda, la madurez, el aplomo si se quiere, la anulación también, de quien está más bien de vuelta. Esta doble condición del poeta como viajero, en la poesía de Saer, se decanta de alguna manera en las figuras del joven Rubén Darío ("Rubén en Santiago") y el viejo Li Po (“El viejo entre las hojas").

La condición de viajero, que es fundamental para comprender la obra de Rubén Darío, es la clave que Saer propone para leer su propia poesía. Si en el viajero barcos, trenes, aviones, muelles, andenes, aeropuertos, ciudades, partidas y llegadas, se organizan en función de un objetivo, lo difícil en Darío es encontrar justamente el trazo nítido que identifique 
un rumbo: que el punto de partida explique un destino; o, si se quiere: que el destino justifique una distancia. Cuando parte, Darío se aleja de algo más complejo que la Nicaragua natal, puesto que el impulso que hace posible tomar un barco, como él lo señala, en medio de un terremoto, se produce en un estado como de embriaguez o ensoñación ("Desperté horas después y fui sobre cubierta. A lo lejos quedaban las costas de mi tierra. Se veía sobre el país una nube negra" ${ }^{8}$ ). Y no es más claro el "destino" de ese viaje, sea cual fuere la forma que logra, que se cristaliza mucha veces en la ciudad de París (o en su ilusión). Es en esta clave que debe entenderse la relación de $A z u l \ldots$ con el viaje a Chile, el lugar que ocupan en la génesis de este libro ciudades como Valparaíso y Santiago, la relación de Prosas profanas con la ciudad de Buenos Aires y la de Cantos de vida y esperanza con Europa (en particular con ciudades como Madrid o París). Estos países, estas ciudades, que fueron patrias adoptivas del poeta, de las cuales se despide en algún momento, no son lugar de llegada ni partida. Especie de estado puro del viaje es su situación.

Pero volvamos a la imagen del joven poeta en la estación de trenes de Santiago. Saer retoma este relato en "Rubén en Santiago", un poema extenso, de una modalidad de escritura "narrativa", o al menos que pone en tela de juicio los límites entre poesía y narración. Rondando el marco, además, del género de la "Biografía". Límites particularmente complicados en la medida que el poema sigue, o podríamos decir: lee, el relato autobiográfico de Darío. Por otra parte, el viaje del poeta se desarrolla en paralelo con un viaje en tren de París a Bretaña. Desde el comienzo, los límites entre ambos viajes se confunden: "Apenas si había salido de la Gare de Montparnasse"... ¿Había salido quién, yo o él? De hecho quien viaja parece estar leyendo, pasando las páginas de un libro.

Si nuestro lector-personaje, el que va en el tren de París hacia Bretaña, avanzara en la lectura del "libro sobre Darío", encontrará, como una serpiente que se muerde la cola, los viajes que el mismo Darío solía hacer a Bretaña cuando vivía en París. Cuando la lectura termina, hacia el final del poema, la lectura del libro biográfico pero también la del poema, todo deviene de pronto escritura:

y únicamente la mano decrépita, deslizándose de izquierda a derecha y sembrando, con tinta roja, sobre las hojas blancas,

\footnotetext{
${ }^{8} C f r$. la descripción de la partida de Nicaragua, en barco, que hace Darío en su autobiografía, op. cit., p. 32-33.
} 
unos signos incomprensibles

en los que otros dicen oír

el canto de las estrellas.

La poesía de Saer, reunida en un solo libro, que lleva el título paradójico de El arte de narrar, evoca en su conjunto el viaje rubendariano.

Saer comienza a escribir y publicar poesía a mediados de los años 50; la fecha que da inicio a la primera sección del libro, que lleva el mismo título de "El arte de narrar", la de 1960, es la misma que da inicio a su obra narrativa.

A partir de un conjunto de poemas publicados en los Cuadernos hispanoamericanos de Madrid del año 1970, con el título de "Poetas y detectives", y luego con las cuatros ediciones de El arte de narrar en libro, cada publicación demarca claramente las etapas de una escritura en proceso, en progresiva ampliación. Por otra parte todas estas etapas de "publicación" trazan, como los tramos de un viaje por distintas ciudades, un largo ensayo de regreso al país. Hablamos de un viaje que se inicia en la ciudad natal, con los primeros poemas, anteriores a toda narración, publicados en el diario El Litoral, a mediados de los años 50, y que sigue (el viaje), de país en país, intentando "la vuelta completa". De Santa Fe a Madrid se fue publicando, decíamos, pasando luego por Caracas, Venezuela, con la primer edición propiamente en libro de $E l$ arte de narrar (Fundarte, 1977) hasta llegar a la segunda edición, con la vuelta a Santa Fe (Universidad del Litoral, 1988). Cuando esta vuelta se concreta, han pasado en algunos casos treinta o cuarenta años de la escritura de los poemas de la colección. Sigue una tercera edición, bilingüe, en Saint-Nazaire (MEET-Arcane 17, 1990) y es finalmente la cuarta edición, en Buenos Aires (Seix Barral, 2000), la que marca el regreso definitivo y el encuentro, en el país natal, con un público amplio $^{9}$. En cada una de estas ediciones el texto se va ampliando con la incorporación de capítulos y poemas, como si se tratara de una novela por entregas.

A pesar de tratarse de una escritura en proceso, de la cual dan cuenta muy globalmente el marco de años establecidos por las secciones en que se organiza el libro, El arte de narrar apenas enseña la génesis de su escritura ${ }^{10}$. Es algo que recién se podrá ir descubriendo con el

\footnotetext{
${ }^{9}$ Citamos en función de esta última edición.

${ }^{10}$ Estas secciones son cuatro y están definidas de la siguiente manera: "El arte de narrar
} 
trabajo sobre los manuscritos ${ }^{11}$. De todos modos podemos esbozar como hipótesis, al menos hasta donde podamos justificarla, la relación estrecha que establece la poesía de Saer con el tema del viaje.

Muchos poemas de El arte de narrar son entonces el resultado o el registro de un viaje, de lecturas hechas durante un viaje o pensadas como viaje (el poema "Rubén en Santiago" reúne ambas posibilidades) aunque las referencias concretas al viaje mismo, como por ejemplo lugares y fechas, se borran o se disimulan detrás de personajes o temas literarios. Esto es lo que ocurre con varios poemas de la primera sección del libro, que lleva como título "El arte de narrar" (1960-1975), por ejemplo en "Dylan Thomas en América" ("En los aviones y en los trenes, uno / se siente sólido y eterno"), en "Lo que cantan las sirenas" ("la discordia perpetua del llano y la geometría"), "El viejo entre las hojas" ("Un mes todavía para llegar, / un mes todavía para llegar / -cantaban los marineros- / pero si me dieran la eternidad de este momento en que busco / ver el humo flotando por encima de la costa / sería indefinidamente un mes más joven"); es el caso también de "Elegía Pichón Garay" (que termina con esos versos: "Bienaventurados / los que están en la realidad / y no confunden / sus fronteras") y es el caso, finalmente, de "Rubén en Santiago", que parafrasea todos los viajes de Rubén Darío ("Viajando, / se percibe, de golpe, el tamaño del mundo").

Esta relación de El arte de narrar con el tema del viaje, se pone de relieve en casi todos los poemas de su tercera sección: "Noticias secretas (1976-1982)", cuyo título sin duda alude al informe que presentan al Rey de España en el siglo XVIII, de regreso de su viaje por los territorios de la colonia, Jorge Juan y Antonio de Ulloa, y que lleva por título justamente Noticias secretas de América. El título de esta sección refiere entonces el célebre viaje de Juan y Ulloa, pero también, en un plano biográfico, si se tiene en cuenta el período mencionado (1976-1982), la imposibilidad de Saer de viajar a Argentina durante la dictadura militar. El título de esta sección, "Noticias secretas", implica varios planos de sentido, que van desde lo cultural a lo biográfico, pasando incluso por las condiciones de escritura de los poemas.

(1960-1975)", "Por escrito (1960-1972)", "Noticias secretas (1976-1982)", "La guitarra en el ropero (1981-1987)".

${ }^{11}$ Una edición crítica de El arte de narrar deberá, por lo menos, recomponer las fechas y en lo posible la situación de la escritura de los poemas que componen el libro. 


\section{A modo de conclusión}

Todo viaje, decíamos, es, en definitiva, algo personal. La estela única de un corte-preciso y fugaz- entre el espacio del pasaje y el tiempo de la experiencia. La escritura del poema también. Y aquí la diferencia entre poema y novela resulta un poco más nítida. El poema es irreversible. La novela, en cambio, un arte de la reversión.

La pregunta es otra, o quizás una variación de lo mismo: ¿dónde comienza a revelarse el significado preciso de un punto de partida, cuándo se define el de llegada?

Si volvemos, entonces, una vez más a la imagen del joven poeta en la estación de Santiago, podemos verificar, como para terminar, que el tratamiento que hace Saer del relato autobiográfico de Rubén Darío evita el encuentro con aquel extraño que, volvemos a citar a Darío, lo "envolvió con la mirada". El poema de Saer, si se quiere, encuentra y mira al joven poeta un instante antes, cuando se queda solo en el andén: "En este / momento él está solo, en la estación de Santiago, / llevando una valija atada con un hilo y un traje oscuro / liviano, que ya resultaba insuficiente / en Valparaíso e incluso en el vapor: en semejantes / situaciones nos deposita el mar de este mundo".

En el poema de Saer, una nueva mirada se posa sobre el joven Rubén Darío, la mirada de un par, amigable, que considera toda su poesía, como si pudiera abrazarla en su totalidad: las posibilidades del joven y las del viejo... El inicio del viaje pero también su destino. El andén, cuando se llega por primera vez a una ciudad, es una situación ideal para representar el estado poético. 